\title{
Evidence that a humoral factor possessing relaxin-like activity is responsible for uterine quiescence in the late pregnant rat
}

\author{
D. G. Porter and Sandra J. Downing \\ Pre-Clinical Veterinary Studies, Department of Anatomy, The Medical School, \\ Bristol BS\& ITD, U.K.
}

\begin{abstract}
Summary. When post-partum ovariectomized rats were linked to 21-day-pregnant rats by a cross-circulation system their myometrial activity was almost completely inhibited. No reduction in activity was induced by cross-circulation with other post-partum rats, or with rats in which myometrial activity had been suppressed with oestrogen. Changes in uterine activity could not be correlated with alterations in arterial hood pressure occurring during the experiments. Uteri rendered inactive by cross-circulation were found to be responsive to oxytocin. It is concluded that a humoral myometrial inhibitor is present in late pregnancy in rat blood and the possibility that it is relaxin is discussed.
\end{abstract}

\section{Introduction}

Parturition in the rat is a highly co-ordinated process. The timing of parturition in rats is regulated by the photoperiod which has prevailed throughout pregnancy (Lincoln \& Porter, 1976) but is presaged by a complex sequence of changes in the tissue and plasma levels of a number of hormones (Yoshinaga, Hawkins \& Stocker, 1969; Wiest, 1970; Bast \& Melampy, 1972; Waynforth \& Robertson, 1972; Labhsetwar \& Watson, 1974; Pepe \& Rothchild, 1974). The work of Boer, Lincoln \& Swaab (1975) suggests that one function of these endocrine changes may be to bring the uterus to a state of preparation in which it will respond to a signal of central origin by labour contractions. During the last $24 \mathrm{~h}$ before parturition, the uterus of the rat exhibits little spontaneous activity in vivo but is responsive to oxytocic substances (Fuchs, 1969; Fuchs \& Poblete, 1970). The mechanism which engenders this condition is not understood. In some species, progesterone is a potent inhibitor of both spontaneous activity and sensitivity to oxytocin, but one of the endocrine changes preceding parturition in the rat is a decline in progesterone titres to low levels by Day 21 (Wiest, Kidwell \& Balogh, 1968; Csapo \& Wiest, 1969; Labhsetwar \& Watson, 1974; Bartholomeusz, Bruce, Martin \& Hartmann, 1976), and it is improbable that progesterone is responsible for the altered activity. Moreover, recovery of oxytocin sensitivity from the progesterone 'block', in the rabbit for example, is normally accompanied by a steady increase in spontaneous activity (Csapo \& Takeda, 1965; Porter, 1968a), and there is now accumulating evidence (Melton \& Saldivar, 1966; Fuchs, 1974; Porter \& Challis, 1974) that progesterone does not inhibit activity of the uterine muscle of the rat. Nevertheless, it seems likely that the pre-partum quiescence might be attributable to humoral factors because the activity of the uterus is in general regulated by hormones. We therefore investigated this possibility by means of a crosscirculation technique.

\section{Materials and Methods}

The 30 Wistar rats were from the Departmental colony in which animals have a median parturition time of 13:13 h on Day 22 (Lincoln \& Porter, 1976). Non-pregnant animals were ovariectomized (tribromoethanol anaesthesia) 1 day post partum and equipped with intrauterine recording balloons (which could be increased to $2 \mathrm{ml}$ volume without ceausing dsignifieant wall tension) which were $2: 02: 46 \mathrm{PM}$ 
connected to catheters brought subcutaneously to the exterior. The balloons were installed and filled with water to give a volume of $0.45 \mathrm{ml}$ several days before the cross-circulation experiments to permit full recovery. Intrauterine pressure was monitored from these animals for at least $24 \mathrm{~h}$ before the experiment, as well as throughout the cross-circulation and the recovery periods. For the crosscirculation experiments the rats were anaesthetized throughout with sodium pentobarbitone $(5 \mathrm{mg} /$ $100 \mathrm{~g}$ body weight) and linked together in pairs by means of cannulae which joined the carotid artery of one animal to the jugular vein of the other. The cannulae were passed through a peristaltic pump (Harvard Apparatus) so that flow $(2.2 \mathrm{ml} / \mathrm{min})$ to and from the two animals in each cross-circulation experiment was identical. Each animal was given 500 units heparin i.v. and arterial blood pressure was monitored in the non-pregnant partners. A tracheotomy was performed in all animals and an endotracheal cannula inserted to establish a clear airway. In each of 8 experiments, one non-pregnant animal was linked to a 21-day pregnant rat for a period of $60 \mathrm{~min}$, and in the remaining experiments non-pregnant animals were linked to other non-pregnant animals. The non-pregnant pairs served as controls and were divided into two groups: 3 pairs consisted of untreated animals only, "crosscirculated' for $60 \mathrm{~min}$, and one member of each of the remaining 4 pairs was given a subcutaneous injection of $5 \mu \mathrm{g}$ oestradiol benzoate at 20 and $8 \mathrm{~h}$ before the start of 'cross-circulation' for $90 \mathrm{~min}$. Before each 'pregnant $\times$ non-pregnant' cross-circulation experiment the blood of the non-pregnant partner was circulated through the peristaltic pump (i.e. 'self-circulation') for 30 min. Three 'pregnant $\times$ non-pregnant' experiments were performed to determine whether the procedure affected oxytocin sensitivity. When the non-pregnant partners exhibited cessation of intrauterine pressure cycles during the cross-circulations they were injected intravenously with $10 \mathrm{mu}$ oxytocin in $0.1 \mathrm{ml}$ saline. Crosscirculation was continued for the duration of the oxytocin response and intrauterine pressure was then monitored continuously until activity had returned to pretreatment levels. The temperature of the animals was maintained by means of lamps and was monitored by checking the rectal temperature at regular intervals. Any animal exhibiting signs of respiratory distress was ventilated with a $95 \%$ $\mathrm{O}_{2}+5 \% \mathrm{CO}_{2}$ mixture by means of a Harvard rodent respirator connected to the endotracheal cannula.

At the end of each experiment the animals were killed before regaining consciousness.

Intrauterine pressure records obtained from the experiments were analysed in 10 min sections. The frequency of pressure cycles was noted for each period as well as the maximum and mean amplitude. A pressure cycle was defined as a rise of pressure above 'resting pressure' of $10 \mathrm{mmHg}$ or more which was followed by a fall in pressure of not less than $10 \mathrm{mmHg}$. The data obtained were analysed statistically by using a paired $t$ test for comparisons of the uterine activity in the same animal before, during and after experiment and simple $t$ tests for group comparisons.

\section{Results}

\section{'Non-pregnant $\times$ pregnant' cross-circulations}

Uterine activity (both amplitude and frequency of pressure cycles) declined significantly in the 6 non-pregnant animals linked to pregnant animals (Text-figs 1 and 2). Thus the frequency of pressure cycles fell from 6-7 to 1-3 cycles/10 min during the 60-min cross-circulation period $(P<0.02$ paired $t$ test $; P<0.01$ group comparison). The fall in frequency was so marked that total quiescence was induced in all animals for periods of at least $30 \mathrm{~min}$ and up to $90 \mathrm{~min}$ duration. There was a slow recovery to about 5 cycles $/ 10 \mathrm{~min}$ by $100 \mathrm{~min}$ after the end of the cross-circulation period. Mean amplitude also showed a fall from $40-45$ to about $18 \mathrm{mmHg}$ pressure about $20 \mathrm{~min}$ after the start of the cross-circulation $(P<0.05)$. Although frequency remained low for some time after the end of the cross-circulation, the amplitude of the contractions that did occur increased during the second part of the cross-circulation and were not significantly different from pretreatment levels by the end of the period.

'Non-pregnant $\times$ non-pregnant' cross-circulations 

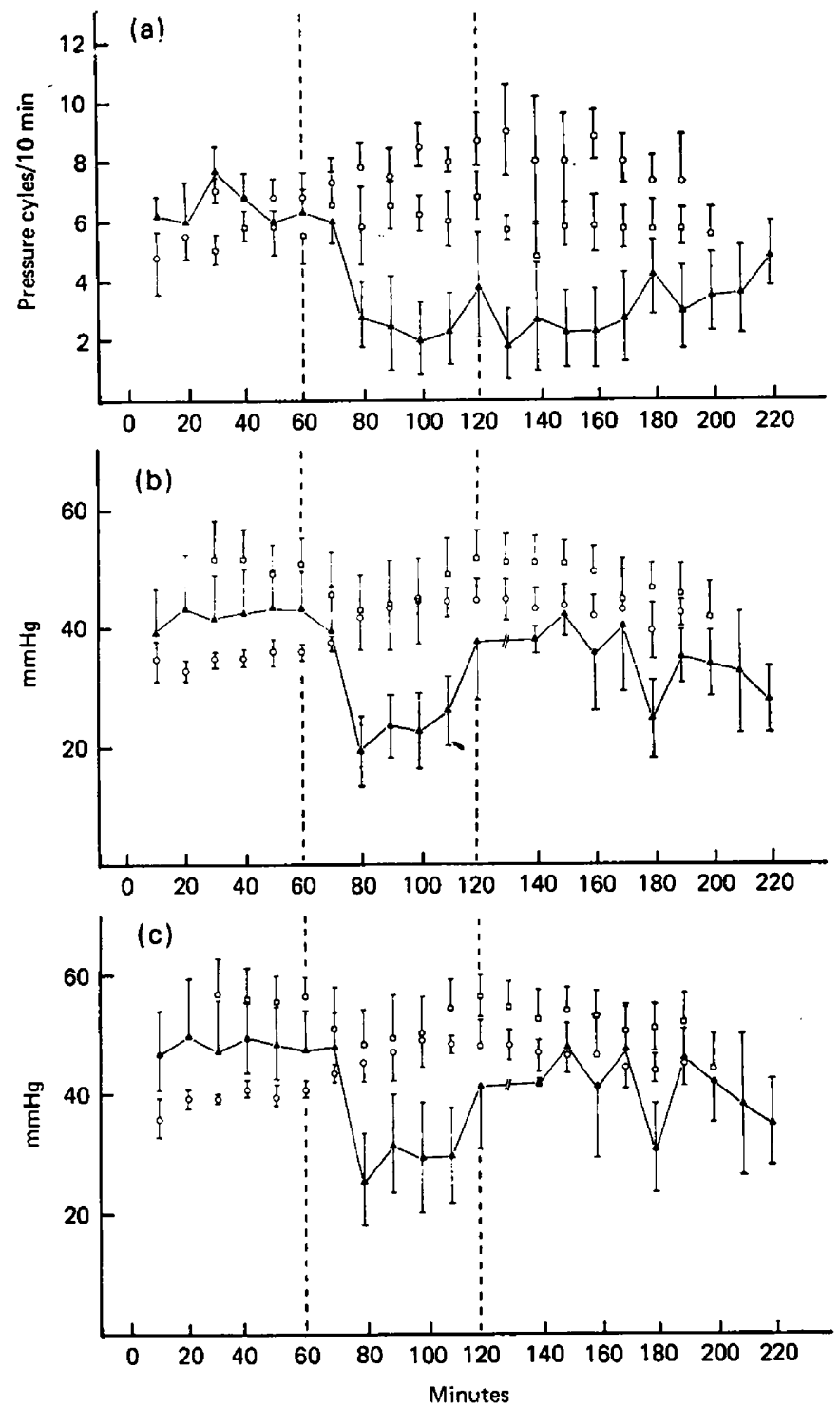

Text-fig. 1. Graphs showing changes in (a) frequency, (b) mean amplitude and (c) maximum amplitude of intrauterine pressure cycles $( \pm$ s.e.m.) of post-partum untreated rats linked by a cross-circulation technique to pregnant $(\Lambda, n=8)$, post-partum untreated $(\square, n=6)$ and post-partum oestrogen-treated $(0, n=4)$ partners. During the $30 \mathrm{~min}$ before cross-circulation the animals were self-circulated. The 60-min crosscirculation period is indicated by the vertical lines; the cross-circulations involving oestrogen-treated animals were continued for $90 \mathrm{~min}$ (see text).

the 60-min cross-circulation period (Text-figs 1 and 2). Mean frequency was about 5-6 cyles/10 min before cross-circulation and remained at that level throughout the experiment. Mean and maximum amplitude of pressure cycles, however, showed a slight transient decline at the onset of the crosscirculation but this was not significant.

'Non-pregnant $\times$ oestrogen-treated non-pregnant' cross-circulations

In these experiments the untreated animals exhibited no decline in uterine activity (Text-fig. 1).

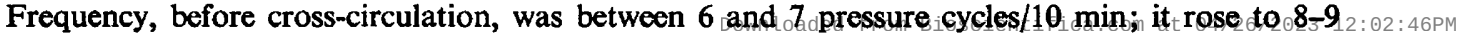


6нимш

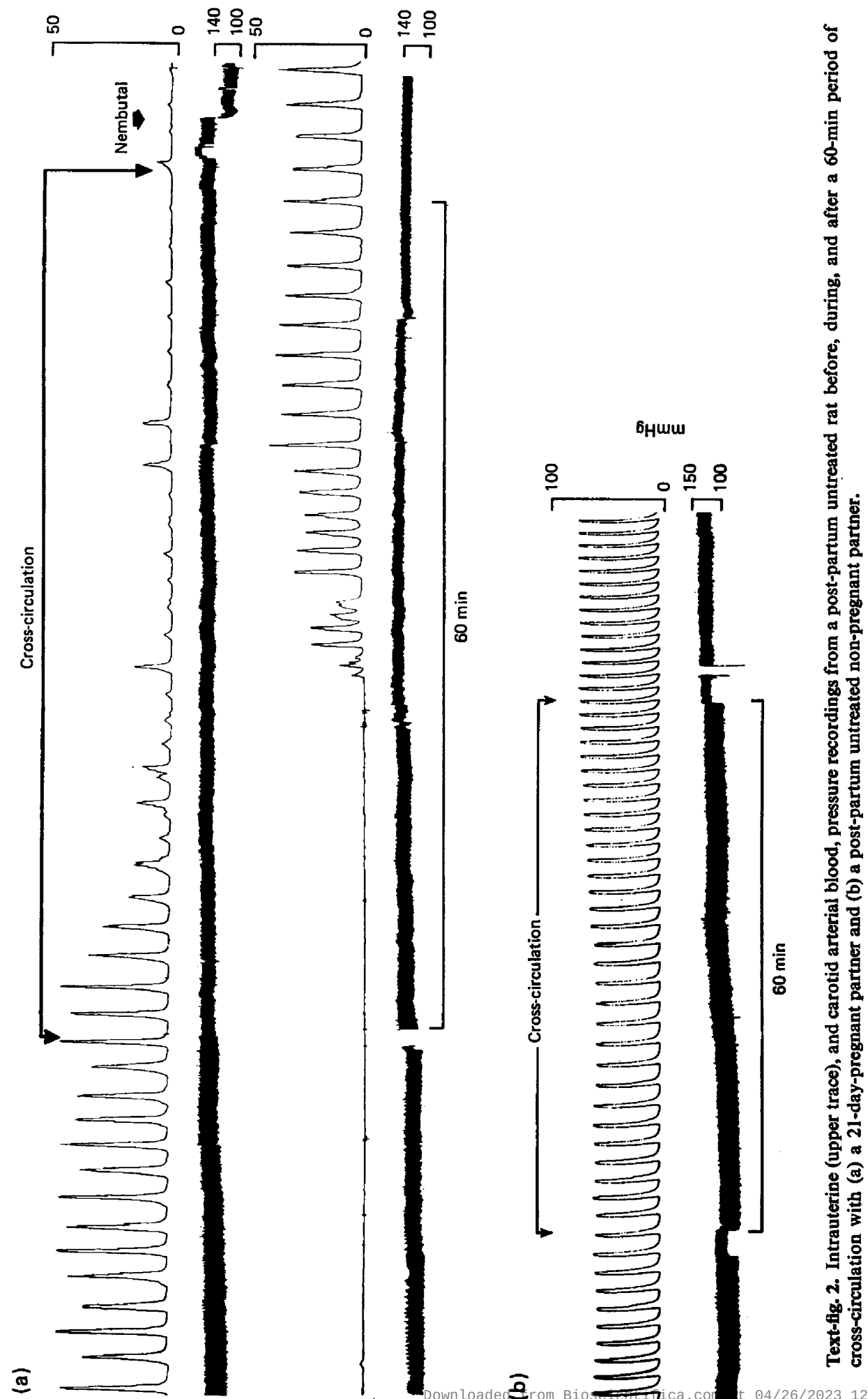

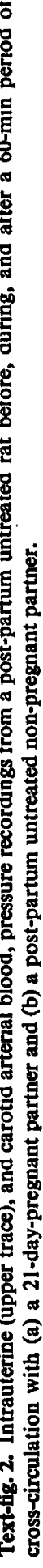


cycles $/ 10$ min during the cross-circulation period $(P<0.05)$ but fell to pretreatment levels by the end. The mean amplitude also rose slightly from $35 \mathrm{mmHg}$ pressure before to $45 \mathrm{mmHg}$ at the end of the experimental period. No increase in activity of the uteri of the oestrogen-treated rats occurred.

\section{Oxytocin tests in 'pregnant $\times$ non-pregnant' cross-circulations}

When the 3 non-pregnant animals exhibited total uterine quiescence after being linked to their pregnant partners, oxytocin was administered. In all cases a response was evoked which consisted of a burst of about 5-10 intrauterine pressure cycles of an amplitude equivalent to that of the pretreatment maximum amplitude (Text-fig. 3). The response lasted up to $20 \mathrm{~min}$. When the uterus again became inactive, cross-circulation was stopped and shortly afterwards spontaneous pressure cycles were resumed at pretreatment amplitude levels, although at reduced frequency.

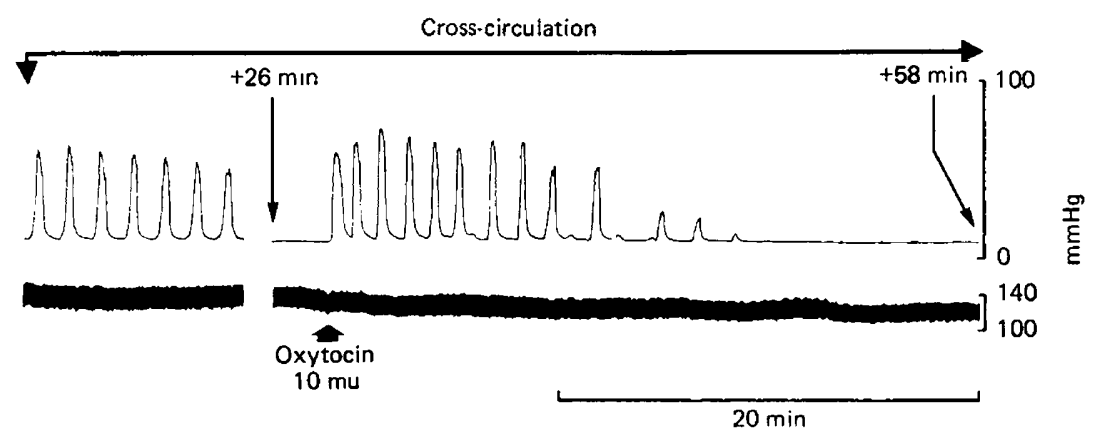

Text-fig. 3. The intrauterine pressure (upper trace) and carotid arterial blood pressure response to $10 \mathrm{mu}$ oxytocin administered intravenously $26 \mathrm{~min}$ after the beginning of cross-circulation with a pregnant partner.

\section{Arterial blood pressure}

Arterial pressure recorded from the carotid cannula remained at a mean level not more than $15 \%$ below the pretreatment pressure throughout the cross-circulation period in 6 'non-pregnant $x$ pregnant' (Text-fig. 2) and 3 'non-pregnant $\times$ non-pregnant' (untreated or oestrogen-treated) experiments. In the remaining experiments carotid arterial pressure fluctuated markedly but in none of these animals could changes in arterial pressure be correlated with changes in intrauterine pressure.

\section{Discussion}

These results demonstrate that when the blood circulations of untreated post-partum rats and 21day-pregnant rats are crossed the uterine activity of the former is inhibited so that instead of consisting of continuous, uninterrupted pressure cycles of high amplitude it becomes characterized by almost complete quiescence, broken if at all by sporadic short trains of pressure cycles of undiminished amplitude. No such change occurs when similar rats are cross-circulated with other untreated or oestrogen-treated post-partum rats.

There are a number of possible explanations for these observations. That the inhibition was attributable to the mechanical effects of circulating blood through a peristaltic pump can be rejected on the grounds that a significant fall in uterine activity was not observed in the control animals, and furthermore self-circulation, i.e. circulating the animal's own blood through the peristaltic pump, failed to alter the level of uterine activity. Other non-specific factors which might account for the results are anaesthesia, lowering of body temperature, and hypoxia. These can be discounted since the control and experimental animals underwent the same anaesthetic procedures, rectal temperature

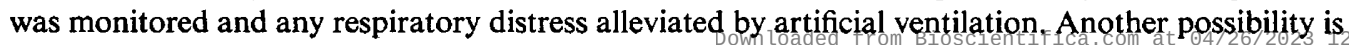


that the effect was due to haemodynamic changes in the recipient animal. This again seem improbable for although mean arterial pressure fluctuated markedly in some experimental and control animals the fluctuations could not be correlated with the changes in uterine activity. Furthermore, in most experimental animals stable arterial blood pressure was recorded throughout the cross-circulation and yet uterine activity still declined.

If an oxytocic substance in the plasma of the non-pregnant untreated animals was responsible for their high level of uterine activity and if this factor was absent from the pregnant partner, then the possibility exists that cross-circulation of the blood of a non-pregnant to a pregnant animal would remove the active substance from the plasma of the former and so reduce its myometrial activity. To test this hypothesis we used the oestrogen-treated ovariectomized rat as a model. The uterus of this preparation exhibits very little spontaneous activity, but because it remains responsive to oxytocin and prostaglandins (Fuchs, 1974; S. J. Downing, S. J. Lye, J. M. C. Bradshaw \& D. G. Porter, unpublished) it can be assumed to have low plasma levels of myometrial stimulants. Therefore, if the inhibition produced by the 'pregnant $\times$ non-pregnant' cross-circulations was due to loss of a stimulant from the latter to the former, the myometrium of an ovariectomized untreated rat should also be inhibited if the animal is cross-circulated with an oestrogen-treated partner. Since this experiment produced no inhibition, even though the cross-circulation period was extended to $90 \mathrm{~min}$, it renders the above explanation unlikely.

We suggest, therefore, that in the blood of the late pregnant rat there is a potent humoral myometrial inhibitor. From the arguments set out in the introduction, it seems improbable that it is progesterone. Examination of the intrauterine pressure recordings from the non-pregnant recipients showed that the inhibitor induced long periods of uterine quiescence. However, the inhibition was not always total; in some animals there were short periods of contractile activity and the inhibited uterus was still sensitive to oxytocin. The impression is created, therefore, of a uterus which was only lightly inhibited. This is consistent with the reports of Fuchs \& Poblete (1970) in that the 21-day-pregnant rat uterus exhibits only sporadic spontaneous activity and is responsive to exogenous oxytocic substances.

This uterine 'inhibitor' resembles the inhibitor reported after similar cross-circulation experiments with guinea-pigs (Porter, 1972) and rabbits (Porter, 1974). Herczeg \& Torok (1976) were unable to obtain comparable results in similar experiments on rabbits, but their paper shows (1) that the records were analysed only for the second $30 \mathrm{~min}$ in each hour of the $3 \mathrm{~h}$ experiments, a procedure which would mitigate any changes occurring gradually over the 30-60 min period and was, in fact, less sensitive than the method adopted by Porter (1974) of analysing the entire record in 10-min sections; and (2) that prior to the experiments unphysiologically high levels of mechanical activity were induced (by an unstated method) in the uteri of the animals and this might reasonably be expected to counteract the delicate (oxytocin sensitivity unimpaired) inhibition produced by a relaxin-like substance. However, the failure of Herczeg \& Torok (1976) to repeat Porter's (1974) results may be more apparent than real because although a non-significant fall in frequency occurred in the control and experimental groups of Herczeg \& Torok (1976), during the second 30-min of recovery (the only one analysed) the fall was significant in the experimental group. At a comparable time in Porter's experiments (1974) the uterine activity of the animals was still inhibited, to about $75 \%$ of the cross-circulation effect.

Porter (1968b, 1977) has postulated the existence of a substance which would create conditions in the uterus such that spontaneous activity is suppressed in order to retain the conceptuses but responsiveness to oxytocic substances is unimpaired. Thus, when a signal is given, possibly by the release of oxytocin, the myometrium can be stimulated into activity, rapidly expelling the young. The nature of the substance responsible is not known but experiments in the guinea-pig (Porter, 1972) have indicated that relaxin has the requisite properties. Relaxin is known to be produced by the corpus luteum of the rat (Anderson, Bast \& Melampy, 1973) and the polypeptide is present in relatively high titres in the serum on Day 21 (O'Byrne \& Steinetz, 1976). There is good evidence in the literature that relaxin inhibits the spontaneous activity of the rat myometrium yet leaves the uterus responsive to oxytocin (Sawyer, Frieden \& Martin, 1953; Miller, Kisley \& Murray, 1957; Miller \& Murray, 1959; Wiqvist, 1959a, b; Paterson, 1965; Porter \& Challis, 1974). It seems reasonable to extrapolate these data from in-vitro experiments or anaesthetized animals to the conscious rat beccause 
Porter $(1971,1972)$ found good agreement between his experiments in vivo and earlier data on the action of relaxin in vitro and in situ (Krantz, Bryant \& Carr, 1950; Felton, Frieden \& Bryant, 1953). Thus the presence of relaxin in the blood on Day 21 requires that this hormone be considered seriously as a possible candidate for the inhibitor of myometrial activity.

The fact that treatment of the non-pregnant rat with oestrogen elicits uterine quiescence (Fuchs, 1974,1976 ; present study) suggests that oestrogen rather than relaxin could be the inhibitor, especially as plasma levels of oestrogen rise on Day 21 of pregnancy (Yoshinaga et al., 1969; Labhsetwar \& Watson, 1974). However, the inhibition produced in the non-pregnant partners during the crosscirculation experiments could not have been due to the transport of oestrogen from the pregnant animal to the recipient for a variety of reasons. The amount of oestrogen transferred would have been too small to have had an effect, and there is also a latency between oestrogen treatment and uterine quiescence which is of the order of at least $6-8 \mathrm{~h}$ (unpublished observations). That oestrogen might stimulate the production of an inhibitory substance is a possibility, but uterine activity failed to decline in the untreated partners linked to oestrogen-treated animals. It is possible that the amount of an inhibitory substance produced in response to oestrogen by the non-pregnant animal might be sufficiently low to escape detection in the cross-circulation system. The question arises, therefore, as to whether oestrogen stimulates the production or release of relaxin, and this is being investigated.

The work was supported by a Grant (AG7/63) from the Agricultural Research Council and by a studentship from the S.R.C. to S.J.D.

\section{References}

Anderson, L.L., BAST, J.D. \& MElampy, R.M. (1973) Relaxin in ovarian tissue during different reproductive stages in the rat. $J$. Endocr. 59, 371-372.

Bartholomeusz, R.K., Bruce, N.W., Martin, C.E. \& HartmanN, P.E. (1976) Serial measurement of arterial plasma progesterone levels throughout gestation and parturition in individual rats. Acta endocr., Copenh. 82, 436-444.

BAST, J.D. \& MELAMPY, R.M. (1972) Luteinizing hormone, prolactin and ovarian 20a-hydroxysteroid dehydrogenase levels during pregnancy and pseudopregnancy in the rat. Endocrinology 91, 1499-1505.

Boer, K., LincolN, D.W. \& SwaAB, D.F. (1975) Effects of electrical stimulation of the neurohypophysis on labour in the rat. J. Endocr. 65, 163-176.

CsAPO, A.I. \& TAKEDA, H. (1965) Effect of progesterone on the electric activity and intrauterine pressure of pregnant and parturient rabbits. Am. J. Obstet. Gynec. 91, 221-231.

Csapo, A.I. \& WIEST, W.G. (1969) An examination of the quantitative relationship between progesterone and the maintenance of pregnancy. Endocrinology 85, 735-746.

Felton, L.C., Frieden, D.H. \& Bryant, H.H. (1953) The effects of ovarian extracts upon activity of the guinea pig uterus in situ. J. Pharmac. exp. Ther. 107, $160-164$.

Fuchs, A.-R. (1969) Uterine activity in late pregnancy and during parturition in the rat. Biol. Reprod. 1, 344353.

Fuchs, A.-R. (i974) Myometrial response to prostaglandins enhanced by progesterone. Am. J. Obstet. Gynec. 118, 1093-1098.

FuchS, A.-R. (1976) Influence of estrogen and progesterone on uterine motility reassessed. Gynec. Invest. 7, 99 .
Fuchs, A.-R. \& Poblete, V.F., JR (1970) Oxytocin and uterine function in pregnant and parturient rats. Biol. Reprod. 2, 387-400.

Herczeg, J. \& TOROK, I. (1976) The stability of uterine activity in non-pregnant rabbits during short-term cross-transfusion with blood from pregnant rabbits. Biol. Reprod. 14, 190-193.

Krantz, J.C., Bryant, H.H. \& CARR, C.J. (1950) The action of aqueous corpus luteum extract upon uterine activity. Surg. Gynec. Obstet. 90, 372-375.

LABhSETWAR, A.P. \& Watson, D.J. (1974) Temporal relationship between secretory patterns of gonadotropins, estrogens, progestins, and prostaglandin-F in periparturient rats. Biol. Reprod. 10, 103-110.

Lincoln, D.W. \& PorTeR, D.G. (1976) Timing of the photoperiod and the hour of birth in rats. Nature, I.ond. 260, 780-781.

Melton, C.E. \& Saldivar, J.T. (1966) Effect of estrogen and progesterone on impulse conduction in rat myometrium. Am. J. Physiol. 211, 835-843.

Miller, J.W. \& MurRay, W.J. (1959) Studies concerning the mechanism of uterine inhibitory action of relaxin-containing ovarian extracts. Fedn Proc. Fedn Am. Socs exp. Biol. 18, 423, Abstr.

Miller, J.W., Kisley, A. \& Murray, W.J. (1957) The effects of relaxin containing ovarian extracts on various types of smooth muscle. J. Pharmac. Exp. Ther. 120, 426-437.

O'Byrne, E.M. \& Steinetz, B.G. (1976) Radioimmunoassay (RIA) of relaxin in sera of various species using an antiserum to porcine relaxin (39377). Proc. Soc. exp. Biol. Med. 152, 272-276.

Paterson, G. (1965) The nature of the inhibition of the rat uterus by relaxin. J. Pharm. Pharmac. 17, 262-264.

Pepe, G.J. \& Rothchild, I. (1974) A comparative study

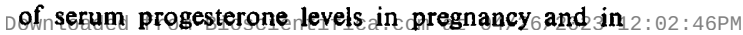


various types of pseudopregnancy in the rat. Endocrinology 95, 275-279.

PORTER, D.G. (1968a) Observations on the development of blastocysts in ectopic sites and the factors involved in the maintenance of pregnancy. Ph.D. thesis, University of London.

PORTER, D.G. (1968b) The local effect of intra-uterine progesterone treatment on myometrial activity in rabbits. J. Reprod. Fert. 15, 437-445.

PORTER, D.G. (1971) The action of relaxin on myometrial activity in the guinea-pig in vivo. J. Reprod. Fert. 26, 251-253.

PORTER, D.G. (1972) Myometrium of the pregnant guinea pig: the probable importance of relaxin. Biol. Reprod. 7, 458-464.

PORTER, D.G. (1974) Inhibition of myometrial activity in the pregnant rabbit: evidence for a "new" factor. Biol. Reprod. 10, 54-61.

PORTER, D.G. (1977) In Discussion in The Fetus and Birth, p. 207. (Ciba Fndn Symp. No. 47.) Eds J. Knight \& M. O'Connor. Associated Scientific Publishers, Amsterdam.

Porter, D.G. \& Challis, J.R.G. (1974) Failure of high uterine concentrations of progesterone to inhibit myometrial activity in vivo in the post-partum rat. J. Reprod. Fert. 39, 157-162.
SAWYer, W.H., Frieden, E.H. \& MARTin, A.C. (1953) In vitro inhibition of spontaneous contractions of the rat uterus by relaxin containing extracts of sow ovaries. Am. J. Physiol. 172, 547-552.

WAYNFORTH, H.B. \& ROBERTSON, D.M. (1972) Oestradiol content of ovarian venous blood and ovarian tissue in hypophysectomized rats during late pregnancy. J. Endocr. 54, 79-85.

WIEST, W.G. (1970) Progesterone and 20 $\alpha$-hydroxypregn4-en-3-one, in plasma, ovaries and uteri during pregnancy in the rat. Endocrinology 87, 43-48.

Wiest, W.G., KidWell, W.R. \& Balogh, K. (1968) Progesterone catabolism in rat ovary, a regulatory mechanism for progestational potency during pregnancy. Endocrinology 82, 844-859.

WiQvisT, N. (1959a) Desensitizing effect of exo- and endogenous relaxin on the immediate uterine response to relaxin. Acta endocr., Copenh., Suppl. 46, 3-14.

WiQvist, N. (1959b) The effect of prolonged administration of relaxin on some functional properties of the non-pregnant mouse and rat uterus. Acta endocr., Copenh., Suppl. 46, 15-23.

YoshinAGa, K., Hawkins, R.A. \& STocker, J.F. (1969) Estrogen secretion by the rat ovary in vivo during the estrous cycle and pregnancy. Endocrinology 85, 103112.

Received 30 May 1977 